Books, videos, cd-roms, dvds and any other relevant items submitted for a review in the BDJ should be addressed to:

Mike Grace, Editor, British Dental Journal, 64 Wimpole Street WIG 8YS

\section{An introduction to orthodontics}

\author{
Laura Mitchell (ed) \\ Oxford University Press, 2001, 2nd edition \\ price $€ 35.00$, pp234 \\ ISBN 019263184-5
}

That orthodontic texts bore and baffle is a common complaint amongst

undergraduates. Later, after qualification, when in their role as gatekeeper, they must decide when and whom to refer an incipient malocclusion if they are to avoid that most dreaded of specialist olympian rebukes "the window of opportunity for this malocclusion is now closed and I can only recommend ....'

The introduction is thankfully different; it ushers the reader on a systematic tour of how malocclusion may arise, be ranked for treatment and then receive appropriate appliance systems and retention. Its principal author is Laura Mitchell whose outstanding Handbook of Dental Care OUP also publish. Lucid sequencing and flow charts ensure that we understand when choices need to be made, for instance, removable versus fixed appliances. Through goal setting at the outset we build in milestones in our delivery of care to avoid adverse sequelae such as unclosed extraction sites or residual overjets and recrowding.

The chapters by Nigel Carter emphasise that facial growth and functional appliances must march together if we are to reduce overjets. His explanations of how growth rotations may defeat functional and other interventions assists greatly. In preventing unwanted tooth movements that may consume space earmarked for resolution of overjets and crowding, Bridget Doubleday's chapter on anchorage offers a useful academic framework.

Could the third edition perhaps incorporate some vignettes by different branches of the orthodontic profession, the cases they treat and the career routes they took or would now recommend?

Orthodontics offers patients much, whether our appliances reduce overjets, unravel crowded teeth or act as adjuncts to ensure that restorations such as bridges or dentures may be more more easily placed and disguised. All boost self-esteem and give their owner a smile and selfconfidence that may translate into better job prospects. This book's 21 chapters offer a fascinating theoretical foundation for the lifelong journey by undergraduates to orthodontic perfection in the exam room and beyond.

\section{M. Hogg [BR 5018]}

\section{Hand to mouth: essays on the art of dentistry}

\author{
E. Curtis \\ London: Quintessence books, 2001 \\ price $€ 27.00$, pp 261 \\ ISBN 0867154098
}

Eric Curtis runs a private practice in Safford, Arizona and holds an assistant professorship in the dental faculty of the University of the Pacific. He is editor of the Journal of the Arizona Dental Association, has published extensively in American journals and has written two books. He received the Hayden-Harris award from the American Academy of the History of Dentistry in 1998 and the Dentist of the Year award from the Arizona Dental Association in 1999. In his preface to Hand to Mouth he explains its raison d'être 'dentistry is as much about people as procedures, and writing ties them together.... Literature, along with other arts and history, adds depth to the dental profession....reinforcing the human qualities - the inherent humanity in what dentists do....A third reason for writing down the links between dentistry and the arts is to examine the fuzzy edges of the dental profession's identity.'

The book is presented in ten 'parts' (chapters) commencing with 'Histories, mysteries and meanings' and culminating in 'Observations'. Each part comprises several short essays or vignettes on related subjects. Each essay is preceded by an illustration relevant to the topic ranging from a Punch cartoon to a portrait of George Washington, his cheeks padded with cotton to disguise the absence of teeth; from eighteenth and nineteenth century lithographs, woodcuts and etchings to contemporary artwork. Many of these are from the author's personal collection; others are taken from various museums, art collections, libraries, journals and books.

The essays explore the wide-ranging ramifications of the dentist/patient relationship, trace the development of dental materials, instruments and procedures and discuss some of the folklore, myths and legends surrounding the practice of dentistry.

The author writes in an easy relaxed prose style blending his own philosophy and experience with anecdotes, literary quotations and references to films, television programes and journals.

To read from cover to cover or to browse at random is a rewarding and entertaining experience. It was a great pleasure to review this book. M. E. Richardson [BR5034]

\section{The complete dental assistant - clinical radiography - CD-ROM}

D. Miles, B. Finkbeiner
USA: New Mentor Group, 2001
Price $\$ 99.00$

Aimed at dental nurses, this CD-ROM is ideal for complementing hands-on training and as a revision tool. A soothing voice guides the user through the five main sections of the course, covering a general overview ('The importance of radiographs'), radiation safety, infection control, speaking to patients (how to reassure patients) and exposing radiographic images. The CDROM is interactive to the extent that you can pause at any time and interrogate the programme's glossary of dental and radiographic terms or view a bibliography for the particular section you are studying at the time. Also, there are occasional 'extra' illustrated notes provided which explain more fully some dental equipment. 

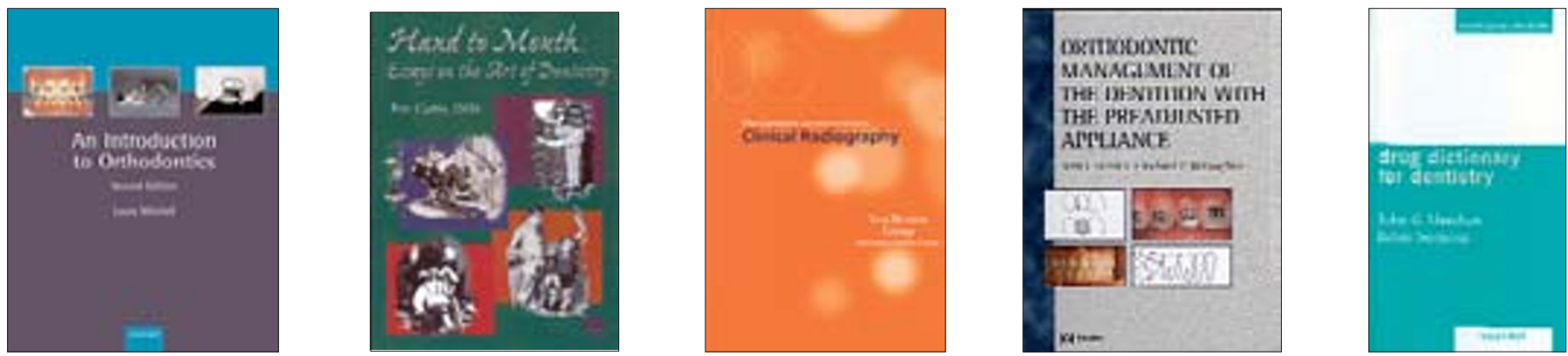

The content experts for this CD-ROM are the American dentist and academic, Dale A. Miles, of the University of Kentucky College of Dentistry and Betty Ladley Finkbeiner, who has written a number of important books including Comprehensive dental assisting and A handbook of four-handed dentistry.

As computer assisted learning (CAL) packages go, this is a good one because it does not try to cram too much in at once and is readily accessible in bite-sized chunks. So it is perfectly possible to study one section per evening, for example, on a home computer, without having to view the complete course in one go. There is a set of self-assessment exercises too within the 'resources' section but unless the nurse is actually involved in positioning the dental film in the patient's mouth for bitewings, many of the exercises are superfluous. However, should they be involved in this then the questions are pertinent and exacting.

With the proviso that UK dental practices do not necessarily operate like American dental practices - for example, lead lined aprons are not now recommended in all patients undergoing dental radiographs with the exception of women who are or may be pregnant - this is a fine learning tool but as with all CAL packages, should not be substituted for real on the job learning experience.

R. Farbey [BR5054]

\section{Orthodontic}

\section{management of the dentition with the preadjusted appliance}

\begin{tabular}{l} 
J. C. Bennett and R. P. Mc Laughlin \\
London: Mosby, 2001 \\
price £135.00, pp 392 \\
ISBN 0723432651 \\
\hline
\end{tabular}

This new book looks at the orthodontic process from a different perspective. The chapters are organised according to the categories of teeth eg incisors, canines, bicuspids etc. By doing this it cuts across traditional approaches to orthodontic philosophy. The book is easy to read and generally well illustrated, although there are a few photographs that are "washed out'. While it is refreshing to approach orthodontic treatment from a different angle it can be confusing for a trainee orthodontist without a good understanding of the principles of treatment.

The authors themselves struggle to fulfil the tooth categorisation. The incisor chapter covers a multitude of topics including tooth eruption for the whole dentition, Bolton analysis, as well as treatment procedures for closure of diastemas, anterior crossbites and unerupted central incisors. The first bicuspid chapter deals with functional occlusion and the author's perspective on the TMD issue and surprisingly does not reference the good reviews on the subject of the relationship of TMD and malocclusion. This follows that pattern of the book where topics are referenced to support a technique or procedure (eg frenectomy, fiberotomy) but the procedure is not necessarily fully evaluated or critically appraised.

Generally, all the cases illustrated were well treated to a high standard. The vast majority of cases illustrated had Class I molar relationships at the beginning of treatment, which makes the approach to tooth categories more manageable.

This is a pleasant book, which is of interest to second and third year postgraduate students as well as specialist orthodontists. The layout of the book does not lend itself as an ideal teaching tool. However, it provides a refreshing approach to the orthodontic treatment process.

S. Richmond [BR5037]

\section{Drug dictionary for dentistry}

J. C. Meechan and R. Seymour
Oxford: OUP, 2002
price $€ 16.95$, pp 434

ISBN 0192632744

This dictionary is a good companion to the Dental Practitoner's Formulary, as it enables the user to find information regarding any medication in more detail with ease. The book is a softback with easy to clean plastic covers and is of a sensible size to be kept easily in one's pocket or at one's side.

The book is aimed at all who practise dentistry whether it be in primary or secondary care. It contains a comprehensive list of drugs that the dentist may encounter in everyday practice: these have been arranged in alphabetical order. The drugs have been listed by their Recommended Non-Propriety Name (rINN) although when required may be found in the index by their British Approved Name (BAN).

For each drug it gives a description, indications, effects on oral and dental structures, effects on patient management and drug interactions. Drugs that may be either prescribed or administered by dentists have been included in greater detail. I found it helpful that information on dosage for both adults and children has been included.

I particularly liked the sections relating to effects on oral and dental structures and considered them to be applicable to not only dentists but to all involved in healthcare. It was remarkable as to how many drugs have an effect upon these tissues.

The section relating to effects on patient management is comprehensive and exceedingly useful. There are many drugs that patients are routinely taking which may have an effect upon the provision of dental treatment; I was particularly surprised by how many drugs may have such an effect.

Furthermore I found it helpful that the section associated with drug interactions is linked with the drug rather than having to seek this information in an appendix.

All in all I would recommend this book to anyone involved in the provision of dentistry as I have found it to be a valuable partner to the Dental Practitoner's Formulary. S. J. Carruthers [BR5035] 